\title{
Measurement of body composition in response to a short period of overfeeding
}

\author{
Hiroyuki Sagayama ${ }^{1,2}$, Yu Jikumaru', Akiko Hirata ${ }^{3}$, Yosuke Yamada ${ }^{3,4}$, Eiichi Yoshimura ${ }^{5}$, Mamiko Ichikawa ${ }^{1}$, \\ Yoichi Hatamoto ${ }^{1}$, Naoyuki Ebine ${ }^{6}$, Akira Kiyonaga ${ }^{3,7}$, Hiroaki Tanaka ${ }^{3,7}$ and Yasuki Higaki, ${ }^{3,7^{*}}$
}

\begin{abstract}
Background: Obesity and overweight are increasing in prevalence in developed countries as a result of changing dietary habits and a lack of physical activity. The purpose of the present study was to evaluate the changes in body composition during short-term overfeeding using the three-component model, which is composed of fat mass (FM), total body water (TBW), and fat-free dry solids (FFDS).
\end{abstract}

Methods: Ten healthy men completed 3 days of overfeeding during which they consumed 1,500 kcal/day more energy than consumed in their normal diets. Body composition was evaluated at three time points: the day before and after their normal diets and the day after the 3-day overfeeding diet.

Results: Before and after their normal diets, there were no significant differences in body weight and composition, but after 3 days of overfeeding, body weight, TBW, and FFDS increased $0.7,0.7$, and $0.2 \mathrm{~kg}$, respectively $(P<0.0001)$. There was no significant difference in FM between the normal and overfeeding diets.

Conclusion: This study suggests that TBW gain contributes to weight gain following a short-term overfeeding.

Keywords: overfeeding, body composition, total body water

\section{Background}

Obesity and overweight are increasing in prevalence in developed countries as a result of changing dietary habits and a lack of physical activity (PA) [1-4]. Both conditions are caused by a chronic imbalance between energy intake (EI) and expenditure (EE). A positive balance between EI and EE is a key factor in weight gain caused by overfeeding or decreasing activity energy expenditure (AEE). Most of the accumulation of excess energy is stored as lipid, mainly triglycerides, with overfeeding [5]. Lipid is ideal for long-term energy store, with little water accumulation in humans. Therefore, huge quantities of triglycerides can be stored with increasing adipocyte size and number during positive energy balance [6,7].

Several previous studies have suggested that EI exceeding EE for 2 to 8 weeks led to increased fat mass (FM) [8-10]. Moreover, the concept of non-exercise activity

\footnotetext{
* Correspondence: higaki@fukuoka-u.ac.jp

${ }^{3}$ Fukuoka University Institute for Physical Activity, 8-19-1 Nanakuma,

Jounan-ku, Fukuoka 814-0180, Japan

${ }^{7}$ Faculty of Sports and Health Science, Fukuoka University, 8-19-1 Nanakuma, Jonan-ku, Fukuoka 814-0180, Japan

Full list of author information is available at the end of the article
}

thermogenesis (NEAT) seems important in energy balance regulation as in the study, which overfed 16 non-obese subjects with $4.2 \mathrm{MJ} /$ day for 56 days; changes in NEAT directly predicted resistance to FM gain from overfeeding [8]. Additionally, there is an association between weight gain and sedentary time during 3 days of overfeeding [11]. Thus, AEE is the most important component of energy expenditure to maintain body weight and composition during overfeeding. However, there is little detailed evidence of changes in body composition when AEE is maintained during overfeeding. Additionally, there is poor information regarding body composition during short-term overfeeding. Therefore, we hypothesized that fat mass would not be gained during overfeeding if AEE could be maintained. Thus, the purpose of the present study was to evaluate changes in body composition during short-term overfeeding using the three-component model, which includes FM, total body water (TBW), and fat-free dry solids (FFDS).

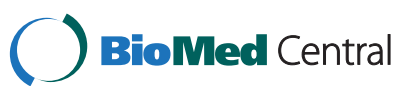

(c) 2014 Sagayama et al.; licensee BioMed Central Ltd. This is an Open Access article distributed under the terms of the Creative Commons Attribution License (http://creativecommons.org/licenses/by/4.0), which permits unrestricted use, distribution, and reproduction in any medium, provided the original work is properly credited. The Creative Commons Public Domain Dedication waiver (http://creativecommons.org/publicdomain/zero/1.0/) applies to the data made available in this article, unless otherwise stated. 


\section{Methods}

Ten healthy, non-obese Japanese men participated in this study (mean \pm standard deviations; age $=23.1 \pm 1.6$ years; height $=171.7 \pm 3.6 \mathrm{~cm}$; body weight $=63.6 \pm 4.5 \mathrm{~kg}$; and body mass index $=21.6 \pm 1.3 \mathrm{~kg} / \mathrm{m}^{2}$ ). All subjects lacked chronic diseases that could affect body composition, metabolism, or daily PA. The subjects were invited to attend an informational meeting and those interested in participating in the study provided written informed consent. The study protocol was approved by the Ethics Committee of Fukuoka University (10-12-02).

The experimental design of the study is shown in Figure 1. Body composition was evaluated at three time points: the day before the 3-day normal diet of the survey period (Baseline $\left.^{1 \mathrm{st}}\left[\mathrm{BL}^{1 \mathrm{st}}\right]\right)$; the day after the 3-day normal diet of the survey period (this day is the same measurement before overfeeding) (Baseline ${ }^{2 n d}\left(\mathrm{BL}^{2 n d}\right)$ ); and the day after the overfeeding diet period (Overfeeding (OF)). Subjects measured their own body weights twice daily for the 6 days (in the morning fasting and again before going to bed) from $\mathrm{BL}^{1 \text { st }}$ to OF. Additionally, subjects measured their own body weights (in the morning fasting) for 2 days during the postintervention observation period and for 2 weeks following completion of OF.

The normal EI survey was defined over a 3-day period (between $\mathrm{BL}^{1 \text { st }}$ and $\mathrm{BL}^{2 \text { nd }}$ measurement). The overfeeding EI survey defined a 3-day period following a normal diet (between $\mathrm{BL}^{2 \text { nd }}$ and $\mathrm{OF}$ measurement). We informed all subjects about their normal EI to maintain that level of EI.
During the 3-day overfeeding period, subjects were overfed with a diet supplying $1500 \mathrm{kcal}$ per day more energy than the 3-day normal EI. Diets were self-selected during normal and overfeeding periods. Excess EI during the overfeeding period was selected based on the energy information shown on food packages.

\section{Body composition measurement}

Subjects came to the laboratory early in the morning on the 3 measurement days after a 12-h fast. All body composition measurements were carried out at the same time each morning after urination and defecation. Height was measured to the nearest $0.1 \mathrm{~cm}$ with a stadiometer. Body weight was measured using a calibrated balance beam scale (Shinko Denshi Vibra Co., Ltd., Tokyo, Japan) to the nearest $0.01 \mathrm{~kg}$, with the subjects wearing only light undergarments. Hydrostatic weighing and stable isotope dilution method estimated body density and total body water. Subjects were administered these stable isotopes using the following protocol: ${ }^{2} \mathrm{H}_{2} \mathrm{O}$, $\mathrm{H}_{2}^{18} \mathrm{O}$, and ${ }^{2} \mathrm{H}_{2} \mathrm{O}$ for $\mathrm{BL}^{1 \mathrm{st}}, \mathrm{BL}^{2 \text { nd }}$, and $\mathrm{OF}$ measurements, respectively. Our previous study provides details regarding the evaluation of body composition using the three-component model [12].

\section{Physical activity and energy intake}

Daily AEE was evaluated using a triaxial accelerometer (Panasonic Electric Works Co., Ltd., Osaka, Japan) [13], which was attached to the waist for about 1 month until

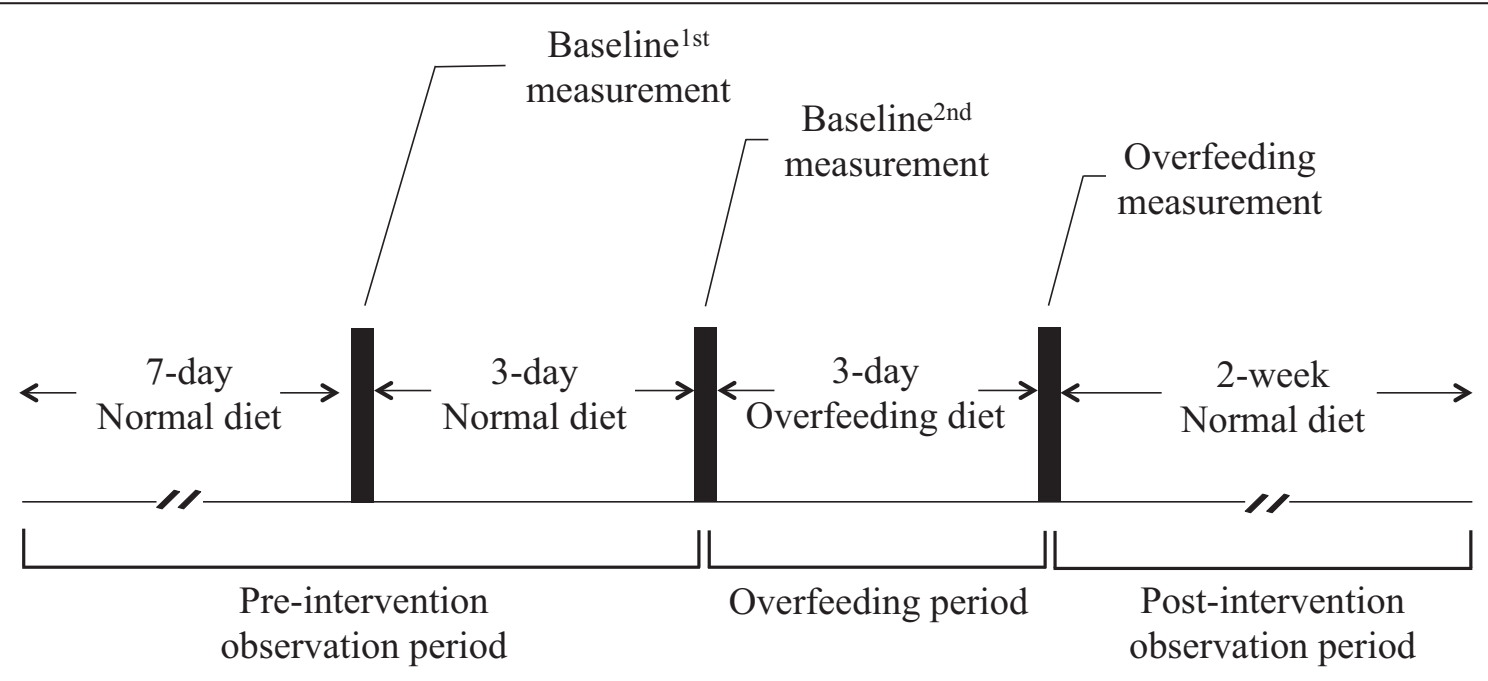

Accelerometer

Body weight

Food record

Figure 1 Study protocol. 
the end of the study (from 1 week before $\mathrm{BL}^{1 \text { st }}$ until the postintervention observation period finished). Subjects were instructed to refrain from vigorous exercise and to maintain their lifestyle for about 1 month. The data of baseline PA were obtained for 7 days with the exception of the first 3 days since attaching the triaxial accelerometer. Subjects strictly maintained baseline PA by checking levels of PA using the triaxial accelerometer during the overfeeding period (between $\mathrm{BL}^{2 \text { nd }}$ and $\mathrm{OF}$ measurement). If the non-wear activity time of the accelerometer exceeded $3 \mathrm{~h}$ in a day, with the exception of the time for taking a bath and sleeping, that day was excluded from the analysis.

All foods and beverages were weighed using a portable digital scale (KS-232; Dretec Co. Ltd., Saitama, Japan) during the $\mathrm{BL}^{2 \text { nd }}$ and $\mathrm{OF}$ measurement periods (3 days). Furthermore, a survey of food intake was conducted using both self-reporting methods and visual records obtained using a digital camera or a mobile phone with a camera. A well-trained registered dietitian checked calculated nutrients from the diet records with the photographs. EI was measured daily from a week before the $\mathrm{BL}^{1 \text { st }}$ until the $\mathrm{OF}$ measurement. All diet records were analyzed using a computerized nutrient analysis program (Excel Eiyoukun Ver. 4.5; Kenpakusha, Tokyo, Japan).

\section{Statistical analysis}

The results are presented as means \pm standard deviations. Comparisons between two groups $\left(\mathrm{BL}^{1 \text { st }}\right.$ versus $\mathrm{BL}^{2 \text { nd }}$ and $\mathrm{BL}^{2 \text { nd }}$ versus $\mathrm{OF}$ ) were made with the paired $t$-test using Microsoft Excel 2010 from Microsoft Office 2010 (Microsoft Corp., Redmond, WA, USA). The intraclass correlation coefficient (ICC) and the coefficient of variation $(\mathrm{CV})$ were used to test the reproducibility of body weight, $\%$ fat, FM, FFDS and TBW measured by the three-component models. Values of ICC above 0.7 were considered as having excellent reproducibility. An alpha of 0.05 was used to denote statistical significance.

\section{Results}

\section{Body compositions}

We first evaluated body composition and measurement reproducibility. All components of body composition did not change between $\mathrm{BL}^{1 \text { st }}$ and $\mathrm{BL}^{2 \text { nd }}$ (Table 1; body weight $=-0.2 \pm 0.5 \mathrm{~kg}, P=0.17 ; \%$ fat $=-0.1 \pm 0.5 \%, P=0.49$; $\mathrm{FM}=-0.1 \pm 0.4 \mathrm{~kg}, P=0.36$; TBW $=-0.1 \pm 0.4 \mathrm{~kg}, P=0.56$; FFDS $=0.0 \pm 0.4 \mathrm{~kg}, P=0.71)$. The ICC for all body composition values was above 0.9 . The $\mathrm{CV}$ for all body composition values was less than $3 \%$.

Body weight, TBW, and FFDS increased during OF compared with $\mathrm{BL}^{2 \text { 2nd }}$ measurements (Table 2 and Figures 2, 3, and 4; body weight $=0.7 \pm 0.5 \mathrm{~kg} ; \mathrm{TBW}=0.7 \pm 0.4 \mathrm{~kg}$; FFDS $=0.0 \pm 0.4 \mathrm{~kg}, P<0.0001)$. There were no significant differences in $\mathrm{FM}$ and $\%$ fat between the $\mathrm{BL}^{2 \text { nd }}$ and $\mathrm{OF}$
Table 1 Change in body composition, coefficient of variation and intraclass correlation coefficient during normal diet

\begin{tabular}{lllll}
\hline & Baseline $^{\text {1st }}$ & Baseline $^{\text {2nd }}$ & CV (\%) & ICC \\
\hline Body weight $(\mathrm{kg})$ & $63.6 \pm 4.5$ & $63.4 \pm 4.1$ & 0.5 & 0.996 \\
Percent of fat (\%) & $14.5 \pm 3.0$ & $14.4 \pm 3.0$ & 2.2 & 0.991 \\
Fat mass (kg) & $9.3 \pm 2.5$ & $9.2 \pm 2.5$ & 2.2 & 0.994 \\
Fat-free dry solid (kg) & $15.5 \pm 0.8$ & $15.5 \pm 0.7$ & 1.3 & 0.946 \\
Total body water $(\mathrm{kg})$ & $38.7 \pm 2.1$ & $38.7 \pm 2.0$ & 0.6 & 0.992 \\
\hline
\end{tabular}

There were no significant differences between $\mathrm{BL}^{1 \text { st }}$ and $\mathrm{BL}^{2 \text { nd }}$ for each of these.CV, coefficient of variation; ICC, intraclass correlation coefficient.

measurements (Table 2). Subjects measured their body weights during the postintervention period. All subjects returned to $\mathrm{BL}^{2 \text { nd }}$ body weights within 2 weeks (5.0 \pm 4.9 days).

\section{Physical activity and energy intake}

During the normal and overfeeding periods, there were no significant differences in levels of PA $(1.6 \pm 0.2$ and $1.6 \pm 0.1$, respectively) and AEE $(835 \pm 261$ and $875 \pm$ $240 \mathrm{kcal} /$ day, respectively) (Table 3 ). Energy, weights of diets, and sodium intakes increased during the overfeeding period $(P<0.05)$. Fat intake significantly increased and carbohydrate intake decreased during overfeeding, affecting the protein, fat, and carbohydrate rate (PFC rate). There was no significant increase in the protein rate.

\section{Discussion}

The major finding of this study is that TBW is the main component of body composition affected during overfeeding when AEE is maintained at the level during normal diets. Our results suggested that the increased body weight for 3 days of overfeeding was mostly TBW. There were no significant differences in body weight or composition at $\mathrm{BL}^{1 \text { st }}$ and $\mathrm{BL}^{2 \text { nd }}$. The ICC values ranged from 0.946 to 0.996 in the body composition measurements in the current study, which is in agreement with previous studies [14]. Thus, the results and methods are thought to be of excellent reproducibility.

The overfeeding of 1,500 kcal per day over 3 consecutive days led to increased body weight, TBW, and FFDS, though there were no significant increases in FM and \%

Table 2 Changes in body composition during overfeeding

\begin{tabular}{lll}
\hline & Baseline $^{\text {2nd }}$ & Overfeeding \\
\hline Body weight $(\mathrm{kg})$ & $63.4 \pm 4.1$ & $64.1 \pm 4.3^{* *}$ \\
Percent of fat $(\%)$ & $14.4 \pm 3.0$ & $13.9 \pm 3.3$ \\
Fat mass $(\mathrm{kg})$ & $9.2 \pm 2.5$ & $9.0 \pm 2.7$ \\
Fat-free dry solid $(\mathrm{kg})$ & $15.5 \pm 0.7$ & $15.7 \pm 0.7^{*}$ \\
Total body water $(\mathrm{kg})$ & $38.7 \pm 2.0$ & $39.4 \pm 1.9^{* *}$ \\
\hline
\end{tabular}

${ }^{* *} P<0.01,{ }^{*} P<0.05$ versus Baseline ${ }^{2 \text { nd }}$ measurement 


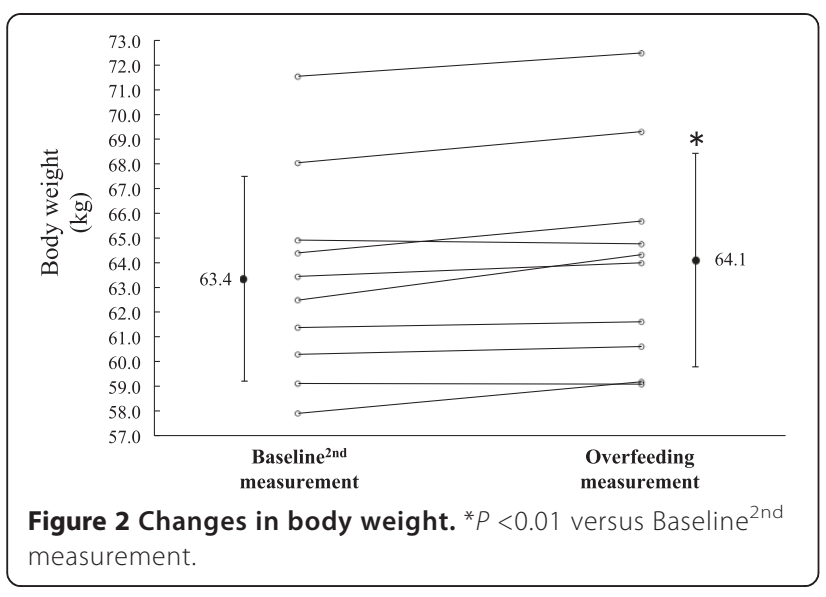

fat. Participants were asked to overeat an average of $4,500 \mathrm{kcal}$ for 3 days, and were able to do so successfully. Assuming that an $\mathrm{FM}$ of $1 \mathrm{~kg}$ is equivalent to $7,000 \mathrm{kcal}$ and that $85 \%$ of the EI would be accumulated as fat in this case, FM was expected to increase by $0.5 \mathrm{~kg}$. However, FM did not increase. In a previous study of overfeeding an excess of 1,000 kcal per day for 8 weeks, increases in body weight, and FM were reported (weight, 1.4 to $7.2 \mathrm{~kg}$; FM, 0.36 to $4.23 \mathrm{~kg}$ ) [8]. Assuming that an FM of $1 \mathrm{~kg}$ is equivalent to $7,000 \mathrm{kcal}$ and that $85 \%$ of the EI would be accumulated as fat in this case, the FM was expected to increase by $6.8 \mathrm{~kg}$. Unexpectedly, body weight and FM in the previous study were not increased as much as expected. Moreover, there were large individual differences in the increases in FM and body weights, as pointed out by some researchers. In particular, the study suggested individual NEAT and sedentary time were different during overfeeding $[8,11]$. We, therefore, instructed subjects in the present study to maintain PA during overfeeding. As a result, the AEE during the 3-day overfeeding period is similar to the AEE during the normal diet period. Thus, PA is not the only factor involved in the lower-than-

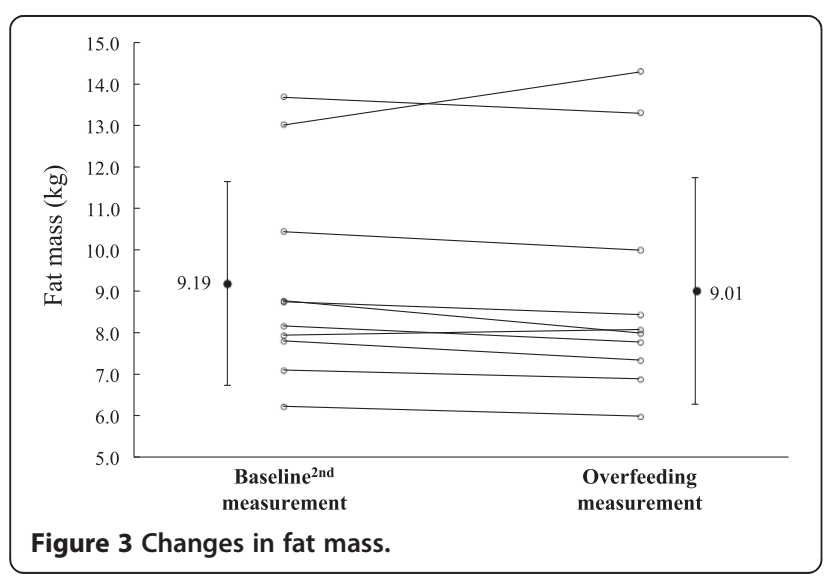

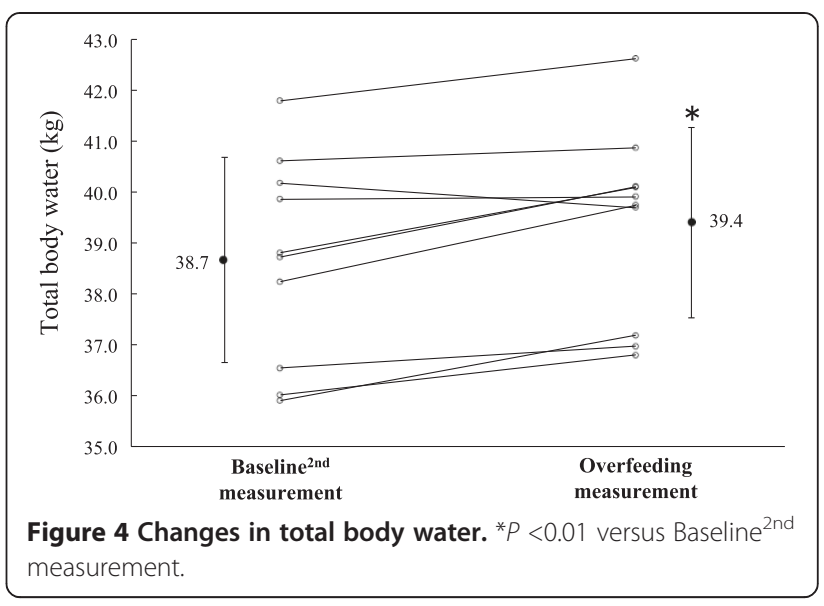

expected increase in FM during overfeeding. Other factors could include an increase in diet-induced thermogenesis [15] and increased lipid catabolism [16]. The unexpected large interindividual variation in the efficiency of weight gain with overfeeding shows that adaptive thermogenesis and other factors are still an issue. Further, the accelerometers worn at the waist may not be able to evaluate arm and leg movement as a component of activity.

Body weight (on average $0.7 \mathrm{~kg}$ ) increased as well as TBW (on average $0.7 \mathrm{~kg}$ ) during the 3 days of overfeeding. Increased TBW could be the result of ingestion of an excess amount of sodium during overfeeding. After the ingestion of dietary sodium, there is a subsequent rise in plasma sodium, and to maintain fluid homeostasis thirst is stimulated, which promotes fluid consumption [17]. In a previous study that compared a high and low salt diet over 50 days, the high-salt diet group had a greater increase in weight compared with the low-salt group [18]. Moreover, dietary sodium is positively associated

Table 3 Changes in physical activity and energy intake before and after overfeeding

\begin{tabular}{lll}
\hline & Baseline $^{\text {2nd }}$ & Overfeeding $^{* *}$ \\
\hline Energy intake (kcal/day) & $2452 \pm 297$ & $3906 \pm 427^{* *}$ \\
Protein intake (kcal/day) & $296 \pm 44$ & $450 \pm 73^{* *}$ \\
Fat intake (kcal/day) & $695 \pm 96$ & $1379 \pm 258^{* *}$ \\
Carbohydrate intake (kcal/day) & $1421 \pm 262$ & $2004 \pm 288^{* *}$ \\
Protein rate (\%) & $12.2 \pm 1.7$ & $11.5 \pm 1.1$ \\
Fat rate (\%) & $28.1 \pm 4.4$ & $35.3 \pm 5.1^{* *}$ \\
Carbohydrate rate (\%) & $58.0 \pm 4.9$ & $51.4 \pm 5.2^{* *}$ \\
Weight of diet (g/day) & $2557 \pm 615$ & $3353 \pm 724^{* *}$ \\
Sodium intake (mg/day) & $4131 \pm 1013$ & $6079 \pm 1856^{* *}$ \\
Physical activity level & $1.6 \pm 0.2$ & $1.6 \pm 0.1$ \\
Active energy expenditure (kcal/day) & $835 \pm 261$ & $875 \pm 240$ \\
\hline **P $<.01$ versus Baseline ${ }^{2 n d}$ measurement. & &
\end{tabular}


with fluid consumption and predicted sugar-sweetened beverage consumption [19]. Following the increase in EI, sodium intake and TBW increased in our study. Thus, water and sugar-sweetened beverage intake could be associated with these increases. The temporary accumulation of sodium may result in increased body weight as a result of transient overfeeding. Glycogen storage, which is known to increase body weight during carbohydrate overfeeding [20], may be another factor to consider. The molecular fraction of glycogen is hydrated by water molecules in a ratio of approximately 1:3, and structurally contains an abundant amount of water [21-24]. Therefore, it has the possibility to contribute to the increase seen in TBW.

The content of the diet was self-selected during the normal and overfeeding periods of our study. The EI of macronutrients during that period significantly increased in terms of PFC. However, the PFC rate was only significantly increased in terms of fat intake. These results suggested that it is possible to consume more energy from fat during self-selected overfeeding. In a previous study comparing overfeeding of high carbohydrate and high fat diets of equal energy, body weight and FM significantly increased in both diet groups. However, that study did not detect a between-group difference [9]. If self-selected overfeeding for 3 days involves a high carbohydrate diet, this may result in the promotion of more weight gain because of increased storage of glycogen and water.

The increased body weight returned to the baseline body weight over an average of 5 days, though there were individual differences ( 0 to 14 days). When subjects were free to follow their regular lifestyles during the postintervention period, their body weights reduced relatively early. These results support the hypothesis that the component of increased body weight in our study was a result of increased TBW.

A limitation of our study is that a diet survey and information regarding bowel movements were not measured during the postintervention period. The EI during the postintervention observation period is a matter of speculation; differences in each subjects' EIs were considered a possible effect of the rapid weight loss. Additionally, the presence, absence, and amount of bowel movements are a reflection of weight cycling during a short period of overfeeding. Additionally, when the fat mass increase started is unknown; thus, further studies are needed to clarify these factors.

\section{Conclusions}

TBW is the main component in overfeeding when AEE is maintained at levels seen during normal feeding.

\section{Abbreviations}

AEE: activity energy expenditure; BL: baseline; CV: coefficient of variation; EE: energy expenditure; El: energy intake; FFDS: fat-free dry solid; FM: fat mass; ICC: intraclass correlation coefficient; NEAT: non-exercise activity thermogenesis; OF: overfeeding; PA: physical activity; PFC rate: protein, fat and carbohydrate rate; TBW: total body water; $\%$ fat: percent of fat.

\section{Competing interests}

The authors state that there are no personal conflicts of interest in the present study.

\section{Authors' contributions}

$H S, E Y, Y Y, Y H, A K$, and $Y H$, conception and design of the study; HS, YJ, EY, $Y Y, M I$, and $Y H$, acquisition of data; $H S, Y J, A H, E Y, Y Y, M I, H T$, and $Y H$, analysis and interpretation of data; HS, YJ, YY, and NE drafting the manuscript; HS, YJ, $E Y, Y H, H T, N E$ and $Y H$, revising the manuscript; and all of the authors approved the final version of the manuscript.

\section{Acknowledgments}

The authors thank the individuals who participated in this study. This work was supported by the Ministry of Education, Culture, Sports, Science and Technology-supported program for the Strategic Research Foundation at Private University (grant number S0801083).

\section{Author details}

${ }^{1}$ Graduate School of Sports and Health Science, Fukuoka University, 8-19-1 Nanakuma, Jounanku, Fukuoka 814-0180, Japan. ${ }^{2}$ Research Fellow of Japan Society for the Promotion of Science, 5-3-1 Koujimachi, Chiyoda-ku, Tokyo 102-0083, Japan. ${ }^{3}$ Fukuoka University Institute for Physical Activity, 8-19-1 Nanakuma, Jounan-ku, Fukuoka 814-0180, Japan. ${ }^{4}$ Section of Energy Metabolism, Department of Nutritional Science, National Institute of Health and Nutrition, 1-23-1 Toyama, Shinjuku-ku, Tokyo 162-8636, Japan. ${ }^{5}$ Faculty of Environmental and Symbiotic Sciences, Prefectural University of Kumamoto, 3-1-100, Tsukide, Higashi-ku, Kumamoto 862-8502, Japan. ${ }^{6}$ Faculty of Health and Sports Science, Doshisha University, 1-3 Tatara Miyakodani, Kyotanabe, Kyoto 610-0394, Japan. ${ }^{7}$ Faculty of Sports and Health Science, Fukuoka University, 8-19-1 Nanakuma, Jonan-ku, Fukuoka 814-0180, Japan.

Received: 16 June 2014 Accepted: 12 August 2014

Published: 10 September 2014

\section{References}

1. Seidell JC: Obesity: a growing problem. Acta Paediatr Supp/ 1999, 88:46-50.

2. James PT, Leach R, Kalamara E, Shayeghi M: The worldwide obesity epidemic. Obes Res 2001, 9(Suppl 4):228S-233S.

3. Deitel M: Overweight and obesity worldwide now estimated to involve 1.7 billion people. Obes Surg 2003, 13:329-330.

4. James PT: Obesity: the worldwide epidemic. Clin Dermatol 2004, 22:276-280.

5. Dériaz O, Tremblay A, Bouchard C: Non linear weight gain with long term overfeeding in man. Obes Res 1993, 1:179-185.

6. Prins JB, O'Rahilly S: Regulation of adipose cell number in man. Clin Sci (Lond) 1997, 92:3-11.

7. Levine JA, Jensen MD, Eberhardt NL, O'Brien T: Adipocyte macrophage colony-stimulating factor is a mediator of adipose tissue growth. $J$ Clin Invest 1998, 101:1557-1564.

8. Levine JA, Eberhardt $N L$, Jensen MD: Role of nonexercise activity thermogenesis in resistance to fat gain in humans. Science 1999, 283:212-214.

9. Lammert O, Grunnet N, Faber P, Bjornsbo KS, Dich J, Larsen LO, Neese RA, Hellerstein MK, Quistorff B: Effects of isoenergetic overfeeding of either carbohydrate or fat in young men. Br J Nutr 2000, 84:233-245.

10. Joosen A, Bakker AHF, Westerterp KR: Metabolic efficiency and energy expenditure during short-term overfeeding. Physiol Behav 2005, 85:593-597.

11. He JY, Votruba S, Pomeroy J, Bonfiglio S, Krakoff J: Measurement of ad libitum food intake, physical activity, and sedentary time in response to overfeeding. PLOS One 2012, 7:e36225.

12. Sagayama H, Yoshimura E, Yamada Y, Ichikawa M, Ebine N, Higaki Y, Kiyonaga $\mathrm{A}$, Tanaka $\mathrm{H}$ : Effects of rapid weight loss and regain on body composition and energy expenditure. Appl Physiol Nutr Metab 2014, 39:21-27.

13. Yamada $Y$, Yokoyama K, Noriyasu R, Osaki T, Adachi T, Itoi A, Naito $Y$, Morimoto T, Kimura M, Oda S: Light-intensity activities are important for estimating physical activity energy expenditure using uniaxial and triaxial accelerometers. Eur J Appl Physiol 2009, 105:141-152. 
14. Tallroth $K$, Kettunen JA, Kujala UM: Reproducibility of regional DEXA examinations of abdominal fat and lean tissue. Obes Facts 2013, 6:203-210.

15. Weststrate JA, Hautvast JG: The effects of short-term carbohydrate overfeeding and prior exercise on resting metabolic rate and diet-induced thermogenesis. Metabolism 1990, 39:1232-1239.

16. Schrauwen P, Lichtenbelt WDV, Saris WHM, Westerterp KR: Changes in fat oxidation in response to a high-fat diet. Am J Clin Nutr 1997, 66:276-282.

17. Stachenfeld NS: Acute effects of sodium ingestion on thirst and cardiovascular function. Curr Sports Med Rep 2008, 7:S7-S13.

18. He FJ, Markandu ND, Sagnella GA, MacGregor GA: Effect of salt intake on renal excretion of water in humans. Hypertension 2001, 38:317-320.

19. Grimes CA, Riddell LJ, Campbell KJ, Nowson CA: Dietary salt intake, sugar-sweetened beverage consumption, and obesity risk. Pediatrics 2013, 131:14-21.

20. Hargreaves M, Hawley JA, Jeukendrup A: Pre-exercise carbohydrate and fat ingestion: effects on metabolism and performance. J Sports Sci 2004, 22:31-38.

21. Puckett $\mathrm{HL}$, Wiley $\mathrm{FH}$ : The relation of glycogen to water storage in the liver. J Biol Chem 1932, 96:367-371.

22. Fenn WO, Haege LF: The deposition of glycogen with water in the livers of cats. J Biol Chem 1940, 136:87-101.

23. Olsson KE, Saltin B: Variation in total body water with muscle glycogen changes in man. Acta Physiol Scand 1970, 80:11-18.

24. King RFGJ, Cooke C, Carroll S, O'Hara J: Estimating changes in hydration status from changes in body mass: Considerations regarding metabolic water and glycogen storage. J Sports Sci 2008, 26:1361-1363.

doi:10.1186/1880-6805-33-29

Cite this article as: Sagayama et al: Measurement of body composition in response to a short period of overfeeding. Journal of Physiological Anthropology 2014 33:29.

\section{Submit your next manuscript to BioMed Central and take full advantage of:}

- Convenient online submission

- Thorough peer review

- No space constraints or color figure charges

- Immediate publication on acceptance

- Inclusion in PubMed, CAS, Scopus and Google Scholar

- Research which is freely available for redistribution 